\title{
Hemeroteca como Estratégia de Leitura e Escrita
}

\author{
Hemeroteca as a Strategy for Reading and Writing
}

\section{Adriana Nascimento BODOLAY *}

Resumo: O presente trabalho apresenta uma reflexão sobre o ensino de leitura e produção de textos no ensino superior. Neste texto, questionamos as estratégias empregadas pelas disciplinas de Língua Portuguesa, no que se refere ao curso de Administração, e propomos que o assunto seja tratado a partir da elaboração de hemerotecas. A atividade com a hemeroteca demonstrou resultados bastante significativos, pois propicia ao alunos o desenvolvimento de habilidades e competências que não são tratadas no âmbito do ensino médio. Ao final, apresentamos como essa atividade pode ser desenvolvida. Destacamos a importância da participação de professores de outras disciplinas, o que confere o aspecto interdisciplinar ao trabalho.

Palavras-chave: Leitura; Escrita; Ensino médio.

Abstract: This paper presents a reflection on the teaching of reading and writing texts in higher education. In this paper, we question the strategies employed by the disciplines of Portuguese, as regards the course of Administração, and we propose that the matter be taken from the elaboration of hemerotecas. The activity with the newspaper library showed very significant results, as it enables students to develop skills and competencies that are not addressed within the high school At the end of this paper, we present how this activity can be develped.

* Professora Adjunta da área de Língua Materna do curso de Letras da Universidade Federal do Pampa, campus de Jaguarão. Contato: adrianabodolay@unipampa.edu.br. 
We highlight the importance of involving teachers of other subjects wich gives the appearance of interdisciplinary work.

Key-words: Reading; Writing; Higher education.

\section{Introdução}

O tema leitura e produção textual na educação superior não era foco de discussão da área até pouco mais de uma década. Com o aumento significativo da oferta de cursos em nível superior, principalmente nas áreas de ciências sociais e aplicadas na região metropolitana de Belo Horizonte, e a consequente percepção de que os alunos oriundos do ensino médio tinham o desempenho pouco satisfatório no que refere à produção textual, observamos ser esse um campo para o desenvolvimento de pesquisas voltadas para a reflexão do docente do nível superior e para a elaboração de atividades pedagógicas destinadas a um trabalho com o grupo de alunos ingressante na educação superior.

Nesse contexto, percebemos a necessidade de trazer a discussão do nosso grupo de pesquisa que investiga o ensino da leitura e da escrita na educação superior em cursos de graduação, de modo a ampliar o debate sobre o assunto. No que diz respeito ao presente trabalho, apresentamos os resultados referentes à pesquisa elaborada pelo grupo com vistas a divulgar uma atividade prática de leitura e produção de textos voltada para esse segmento de alunos. O trabalho foi feito no curso de Administração em uma faculdade da rede particular da cidade de Belo Horizonte.

Sobre o curso escolhido, é interessante ressaltar que o termo administração vem do latim ad-(tendência para) e minister (obediência). Longe do significado original dos dois vocábulos, o curso de Administração visa preparar profissionais que saibam lidar com problemas gerenciais de forma ágil. Além disso, requer do graduando fluência verbal, tanto no âmbito da fala quanto da escrita, uma vez que duas das habilidades focadas no curso são a liderança e o trabalho em equipe.

Além da visão de se formar um profissional para o mercado de trabalho, na Instituição a que nos referimos anteriormente, existe a 
preocupação em formar o leitor/produtor de textos acadêmicos proficiente. Entretanto, o público que tem sido recebido nos primeiros períodos do curso não se mostra preparado para lidar com os gêneros textuais que circulam no meio acadêmico. No nosso ponto de vista, em função dessa demanda, é necessário instrumentalizar os alunos ingressantes de modo que eles possam construir sentidos para as leituras que fazem, bem como fornecer-lhes estratégias para a produção desses mesmos textos.

Dessa forma, como já foi ressaltado, propomos apresentar algumas reflexões a partir da experiência adquirida com docência da disciplina Português Instrumental nos períodos iniciais do curso de Administração. Adotamos o pressuposto que a produção de textos técnicos que fazem parte do domínio acadêmico, como é o caso do resumo, do projeto de pesquisa, do artigo científico, dos relatórios de estágio supervisionado, dentre outros, deve ter o suporte de um modelo de leitura. O trabalho com estratégias específicas na leitura dos diversos gêneros acadêmicos dessa área orienta-nos no sentido de efetivamente contribuirmos para a uma produção de textos eficiente, dentro das regras da língua padrão.

\section{Histórico da disciplina no curso}

Ao investigarmos a função da disciplina Português Instrumental nos cursos de Administração, verificamos que os nomes a ela conferidos variam de instituição para instituição. Designações como Comunicação e Expressão, Redação Técnica ou mesmo Português são atribuídas, sem muita mudança na perspectiva dos conteúdos trabalhados. Percebemos que, menos preocupados com habilidades e competências, o programa gira em torno da discussão sobre teoria da comunicação, noções gramaticais - nesse caso, problemas de língua padrão, como concordância, regência, emprego dos pronomes - e as técnicas de redação comercial, como a produção de cartas, memorandos, atas, dentre outros textos que circulam no meio empresarial.

No âmbito das Diretrizes Curriculares para o curso de Administração (2005, p. 2), afirma-se que: 
Art. $3^{\circ} \mathrm{O}$ Curso de Graduação em Administração deve ensejar, como perfil desejado do formando, capacitação e aptidão para compreender as questões científicas, técnicas, sociais e econômicas da produção e de seu gerenciamento, observados níveis graduais do processo de tomada de decisão, bem como para desenvolver gerenciamento qualitativo e adequado, revelando a assimilação de novas informações e apresentando flexibilidade intelectual e adaptabilidade contextualizada no trato de situações diversas, presentes ou emergentes, nos vários segmentos do campo de atuação do administrador.

Nesse contexto de formação profissional, em que se salientam as habilidades de um administrador, notamos a necessidade de redimensionar os conteúdos, conferindo-lhes um caráter instrumental. Dessa forma, o foco passou a ser o desenvolvimento de habilidades / competências para, de acordo com a diretriz do curso, formar egressos que se comuniquem nas modalidades escrita e falada da língua.

Vale notar que a nossa perspectiva, desde a criação do curso de Administração na instituição objeto desta pesquisa, é discursiva, privilegiando, no interior da disciplina, o contato com textos acadêmicos da área gerencial. Nossa hipótese de trabalho é pautada na premissa de que o aluno que lê textos teóricos, técnicos e científicos, e por consequência os redige, estará apto a compreender e escrever com proficiência diversos outros gêneros que circulam em outras esferas, como é o caso do meio empresarial.

Assim, foram excluídos do programa da disciplina os conteúdos essencialmente teóricos, apesar de nossa prática ser subsidiada por teorias enunciativas. Orientamo-nos, sobretudo, pelo que afirma Bakhtin (1981, p. 154) para quem

[...] a língua não existe por si mesma, mas somente em conjunção com a estrutura individual de uma enunciação concreta. É apenas através da enunciação que a língua toma contato com a comunicação, imbui-se do seu poder vital e torna-se uma realidade. 
Orientando-nos pelo autor, nosso intuito não é discutir as questões teóricas relacionadas ao texto, mas demonstrar aos alunos o que é essencial na leitura e na produção de textos, pautando-nos, sobretudo, nas dificuldades que os alunos apresentam ao lidar com o domínio discursivo acadêmico.

Dentre as principais dificuldades, no que se refere à linguagem, encontramos a formalidade do vocabulário e a pluralidade de vozes que entremeiam esses textos. Identificar esses dois problemas foi a primeira tarefa que orientou o tratamento da leitura dentro do curso. Tal perspectiva foi relevante, pois pudemos selecionar estratégias específicas para tratar essa questão junto aos alunos e caracterizar o caráter instrumental da disciplina no curso.

Vale ressaltar que o trabalho conjunto dos professores no período, no que tange o trabalho multidisciplinar, reforça o trabalho do Português Instrumental. A visão integrada proporcionada pela equipe facilita a compreensão dos conteúdos específicos e a aplicação das estratégias de leitura ensinadas ao longo do semestre corroboram a hipótese de trabalho interdisciplinar (cf. Oliveira, 2007). Esse parâmetro foi de fundamental importância para direcionar o tratamento da escrita, uma vez que tal tarefa é também orientada pelo professor de Português.

Essas características peculiares do curso de Administração da instituição investigada tornaram-se relevantes para a linha de trabalho que ora trazemos neste texto. É necessário que o grupo de docentes tenha uma visão interdisciplinar para que mudanças como essas ocorram. Essa perspectiva não coloca uma disciplina à frente das outras, nem faz com que outras sejam meramente figurativas na estrutura curricular. Ao contrário, todas são fundamentais para a apropriação do conhecimento acadêmico.

\section{Perfil dos alunos ingressantes}

De modo a direcionarmos um tratamento mais adequado às dificuldades apresentadas pelos alunos, coletamos junto à Coordenação de Avaliação Institucional alguns dados referentes aos alunos ingressantes do curso de Administração no ano de 2006. Tais dados foram relevantes, uma vez que nos permitiu constatar o perfil dos alunos de cada curso. Selecionamos algumas informações que nos parecem 
importantes para compreender o perfil do leitor/produtor de textos que recebemos em cada curso.

Dentre os dados coletados, vale destacar aquele referente à faixa etária dos alunos ingressantes naquele período. A tabela a seguir apresenta essas informações:

\begin{tabular}{c|c}
\hline Faixa etária & $\boldsymbol{\%}$ \\
\hline Até 18 anos & $6 \%$ \\
\hline 19 a 24 & $39 \%$ \\
\hline 25 a 30 & $31 \%$ \\
\hline 31 a 40 & $23 \%$ \\
\hline Mais de 40 & $1 \%$ \\
\hline
\end{tabular}

Fonte: Coordenação de Avaliação Institucional - $1^{\circ}$ semestre/2009

Quadro 1 - Porcentagem de alunos por faixa etária - curso de Administração

Percebemos que, no que se refere a esse dado, os alunos ingressantes encontravam-se, em sua maioria (76\%), numa faixa etária até 30 anos. Outra informação que nos chama a atenção diz respeito à origem escolar do aluno. Dos 104 alunos recebidos naquele período, $78 \%$ vieram de escolas públicas da região onde a instituição está localizada. Esse dado, em conjunto ao dado faixa etária, nos revela que esses alunos são fruto da atual escola pública da região metropolitana de Belo Horizonte.

Outro dado que merece destaque é sobre a leitura. O gráfico a seguir nos revela a quantidade de livros lidos pelos alunos no último ano: 


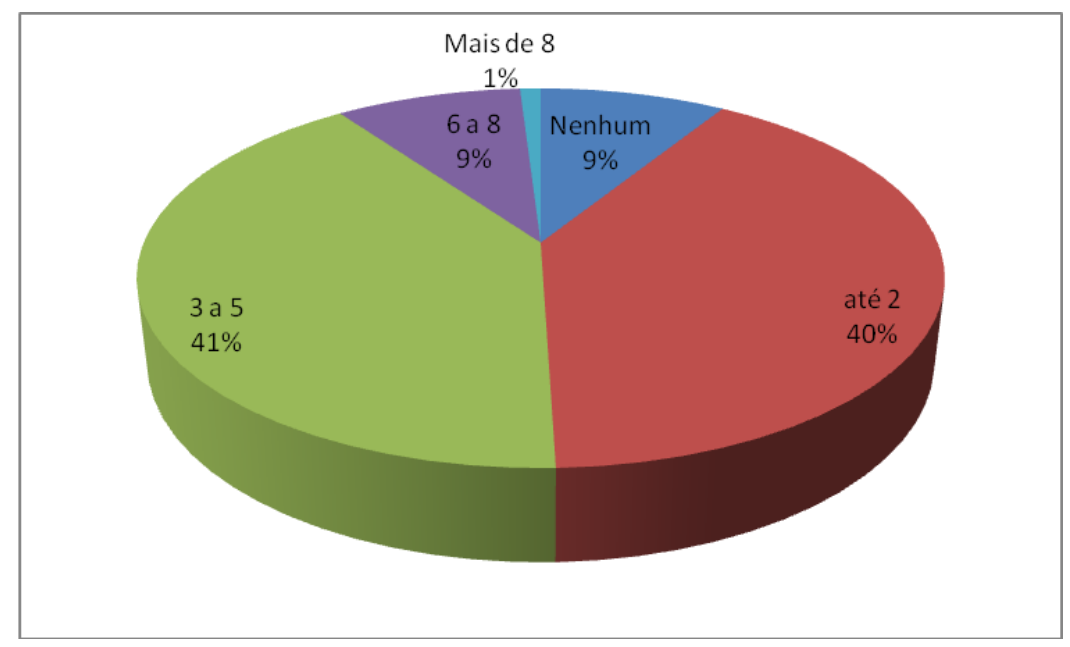

Fonte: Coordenação de Avaliação Institucional - $1^{\circ}$ semestre/2009

Figura 1 - Quantidade de livros lidos durante o ano

Verificamos, assim, que a pouca prática de leitura pode ser um fator que dificulta a inserção desses alunos na realidade acadêmica. Apesar de não termos a informação da qualidade dessa leitura, podemos afirmar, em função da nossa experiência com as turmas ingressantes, que os alunos não lançam mão de estratégias para compreensão dos textos. Isso significa que é necessário instrumentalizálos nesse campo. Ainda mais, é preciso um trabalho conjunto entre o Português Instrumental e as demais disciplinas do período de forma a ensiná-los tais estratégias para alcançarem nível de leitura desejável para iniciantes acadêmicos.

\section{Caracterização dos textos que circulam no curso}

Além da descrição do perfil do ingressante, buscamos, num segundo momento, caracterizar os principais gêneros textuais que circulam no curso de Administração. $\mathrm{O}$ nosso objetivo foi fazer um levantamento de modo a conhecermos de que forma é possível aos discentes construir conhecimento a partir dos textos dessa área. 
Para tanto, adotamos o conceito de gênero textual como "uma instância de realização bem sucedida, de um propósito comunicativo específico, pela utilização de conhecimento convencionalizado4 sobre recursos discursivos e linguísticos" (Bhatia, 1993 apud Bonini, 2003). Dessa forma, os gêneros textuais consistem em "famílias de textos" (cf. Dionísio, Bezerra \& Machado, 2002) que possuem características linguísticas, estruturais e funcionais em comum.

Listamos, a seguir, os gêneros mais utilizados pelos professores no domínio discursivo acadêmico com o objetivo de disseminar o conhecimento. Vale afirmar que a nossa classificação é meramente didática, uma vez que sabemos que a taxonomia dos gêneros não é algo definitivo, pois existem textos que mesclam características, constituindo novos gêneros atendendo, assim, à demanda dos usuários da língua.

a) Textos teóricos: entendemos como textos teóricos aqueles cuja função é disseminar os conceitos básicos de uma área do conhecimento. É o caso de capítulos de livros de Administração e de Economia, os quais são utilizados pelos professores das disciplinas Teoria Geral da Administração e Economia. O público-alvo desses textos são alunos iniciantes nesses cursos já citados.

b) Artigos de opinião: retirados das mais diversas revistas não científicas de grande circulação no país, são textos utilizados pelos professores com a função de suscitar o debate, bem como a tomada de decisão diante de um assunto polêmico. Os assuntos variam de disciplina para disciplina, mas sempre têm como alvo o tema que está em questão no momento, dentro do conteúdo previsto pelo professor. Geralmente são utilizados para esse fim os editoriais, reportagens e entrevistas.

c) Apostilas confeccionadas pelos professores: são textos didáticos elaborados pelos próprios professores da disciplina. Têm como função propor uma reorganização dos conceitos tratados nos textos teóricos, associando o que defendem os principais autores da área à visão do professor. Os exercícios, nem sempre são obrigatórios, mas são utilizados com um objetivo de fixar o conteúdo já ministrado. Podem estar ao final de cada unidade ou de cada tema tratado na disciplina. 
d) Artigos científicos, dissertações e teses: são textos que apresentam resultados de pesquisa científica. São encontrados em revistas de divulgação científica e os professores os utilizam no intuito de contribuir para que o aluno elabore um raciocínio científico no tratamento de assuntos que sejam relevantes para sua formação. Esses textos são a base para a construção do projeto de pesquisa e para o trabalho de conclusão de curso ${ }^{1}$ a serem confeccionados nos períodos posteriores.

Feito esse levantamento, verificamos que mesmo os gêneros textuais mais conhecidos (editoriais, reportagens e entrevistas) são compreendidos com dificuldade pelos alunos, que necessitam de orientação do professor para a construção do sentido. Entendemos que essa dificuldade ocorre porque é necessária uma opinião formada sobre um determinado assunto, tarefa para a qual nem sempre os ingressos estão preparados, pois lhes faltam conhecimentos prévios sobre os mais diversos assuntos.

O mesmo ocorre quando se trata de textos teóricos, artigos científicos, dissertações e teses. Nesse caso, a dificuldade aumenta por se tratar de um novo tipo de raciocínio: o científico. ${ }^{2} \mathrm{Uma}$ das principais dificuldades inerentes a esses textos é a incompreensão de que o conhecimento científico não é normativo e que o posicionamento teórico pode oferecer respostas diferentes para um mesmo problema que se apresenta.

Assim, vimos que se torna imprescindível o levantamento de habilidades/competências para que os discentes possam lidar com a leitura, e, consequentemente, com a produção de textos, tomando por base esses gêneros que listamos anteriormente.

${ }^{1}$ Conforme previsto no Projeto Pedagógico do Curso de Administração da IES investigada, os alunos desenvolvem um relatório de estágio como trabalho de conclusão de curso. $\mathrm{O}$ trabalho passa pelo crivo de uma banca examinadora e os alunos produzem, além do texto escrito, uma apresentação oral desse mesmo trabalho.

${ }^{2}$ Uma das grandes dificuldades apresentadas relaciona-se à identificação e formulação do problema de pesquisa, conforme pudemos observar nas aulas de Metodologia do Trabalho Científico. 


\section{Habilidades e competências para leitura e escrita de textos acadêmicos no curso de Administração}

O conceito de competência e habilidade muitas vezes se confunde no âmbito da literatura especializada. Utilizamos aqui a ideia de Perrenoud (2000) de que "competência é a faculdade de mobilizar um conjunto de recursos cognitivos (saberes, capacidades, informações etc) para solucionar com pertinência e eficácia uma série de situações”. As competências atuam, então, num âmbito abrangente: no nosso caso, a leitura e a escrita de textos acadêmicos de uma determinada área de conhecimento.

Por sua vez, as habilidades, segundo o mesmo autor, são ações no nível micro que permitem resolver situações novas. Assim, no que se refere às habilidades, podemos detalhar da seguinte forma: para criar uma competência como a leitura de textos acadêmicos da área de Administração, existem tarefas que precisam ser executadas - e que nem sempre são feitas - pelos alunos e que devem ser conscientemente aplicadas durante o processo de leitura.

Honsberger \& George (2002) propõem um modelo para a compreensão da formação de competências/habilidades. Apesar de não ser um padrão, conforme apontam as autoras, a ideia dos degraus sugere uma hierarquia e nos direciona no sentido de identificar o nível em que se encontram os alunos e em qual direção devemos caminhar:

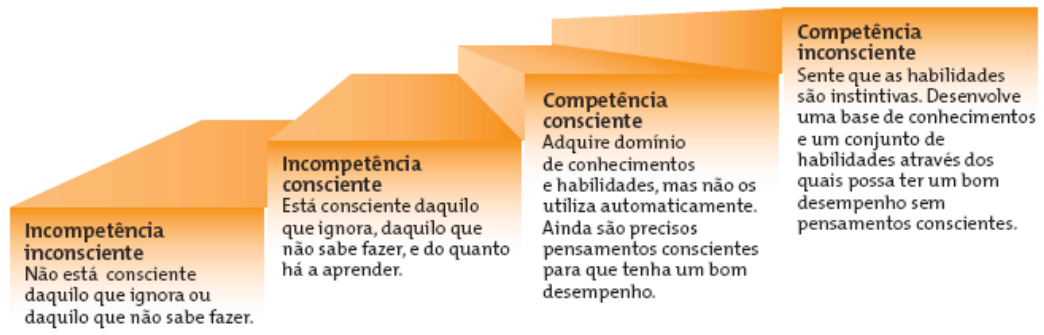

Fonte: Honsberger \& George (2002, p 26). 
Dentre as competências/habilidades elencadas pelo Currículo Básico Comum $(\mathrm{CBC})^{3}$ de Língua Portuguesa, verificamos que aquelas que dizem respeito à contextualização, à tematização e à enunciação ${ }^{4}$ são dominadas satisfatoriamente por apenas $20 \%$ das turmas que fizeram parte desta pesquisa. No âmbito do que verificam Honsberger \& George (2002), podemos afirmar que apenas 10\% dos alunos possuem uma competência inconsciente, ao passo que os outros $90 \%$ estão localizados nos outros três níveis. Grande parte desse percentual (55\%) está concentrado no nível da incompetência consciente, mas não sabem, entretanto, como sair dessa situação.

Assim, tendo em vista tais questões, a proposta para ensino de Português Instrumental para o curso de Administração deve visar à aquisição de habilidades e competências não apresentadas pelos alunos. De uma forma diferente do que se propõe no $\mathrm{CBC}$, o domínio discursivo a ser abordado em sala de aula deve ser o acadêmico, uma vez que é para essa esfera discursiva que pretendemos formar leitores e produtores de textos. A partir desse contexto, procuramos determinar quais seriam os princípios da formação do leitor crítico de textos (inclusive do seu próprio texto), instrumentalizando-os para serem revisores de seus textos.

Nesse sentido, procuramos direcionar o trabalho da disciplina na estrutura do curso para o desenvolvimento das competências/ habilidades de leitura e de produção de textos. Do ponto de vista do conteúdo gramatical, selecionamos aqueles que teriam alguma função na leitura e na produção do texto, como é o caso da pontuação, para a qual são necessários conhecimentos específicos relativos ao funcionamento sintático da língua padrão (análise do período simples e composto). Apesar de parecer contraditório, o resgate desses conceitos são fundamentais para orientar algumas atividades de leitura e de escrita.

${ }^{3}$ Documento elaborado pela Secretaria de Estado da Educação de Minas Gerais. No texto, são enumeradas competências/habilidades necessárias a alunos de ensino fundamental e médio. Todas as competências/habilidades elencadas no presente trabalho foram retiradas do $\mathrm{CBC}$ do ensino médio.

${ }^{4}$ Tomamos por referência a matriz de habilidades, em anexo. 


\section{Sugestão de trabalho de leitura/produção de textos}

Tendo em vista as dificuldades apresentadas pelos alunos, o contexto de origem e os objetivos do curso apresentados anteriormente, propusemos as diretrizes da disciplina, pautadas nas competências leitura e escrita dos gêneros acadêmicos. Muito mais do que oferecer material teórico sobre ambos os assuntos, partimos do princípio do "aprender fazendo", uma vez que só se aprende a ler, lendo, da mesma forma que se aprende a escrever, escrevendo e reescrevendo.

Das diversas metodologias para ensino de língua, escolhemos aquela que valoriza o conhecimento que o aluno de primeiro período tem da língua. Partimos da ideia de que uma aula de Português deve ser participativa e envolvente, pois somente assim é possível motivar os alunos no sentido de criar o gosto pela leitura e pela produção de textos. Dessa forma, nomeamos as aulas de oficinas, momentos privilegiados de construção do conhecimento que vale não apenas para o meio acadêmico, mas para a inserção dos futuros bacharéis no mercado de trabalho.

No âmbito da leitura, então, elencamos algumas oficinas: estratégias de leitura de textos de diversos gêneros, tendo em vista as habilidades/competências específicas. Dentre elas, encontram-se: relação título/subtítulo e as partes subsequentes; elaboração de vocabulário técnico; importância da contextualização no processo de leitura; identificação de termos-chave; hierarquização de ideias; função da polifonia, dentre outros.

Os resultados das oficinas de leitura são observados pelos professores das demais disciplinas do período. É importante salientar que o trabalho se tornou ainda mais proveitoso quando a Instituição promoveu uma capacitação para o corpo docente, a qual tratava de questões relativas à leitura no ensino superior. Sabemos que grande parte dos professores não possui uma formação que privilegia a teoria do texto, mas todos, de alguma forma, possuem a experiência da leitura e da escrita acadêmica. Faltava a eles um momento para pensarem sobre o fato de ser necessário ensinar os alunos a lerem os textos propostos nas suas disciplinas. As estratégias utilizadas pelos professores na sua vivência são repassadas aos discentes, os quais percebem que todos precisam aprender a ler. 
No que refere à produção de textos, o primeiro momento é o da verificação de que um bom texto escrito depende de uma leitura bem feita. Quer seja para a elaboração dos argumentos, quer para o conhecimento do gênero textual, ou mesmo da aquisição do vocabulário, o conteúdo das oficinas de leitura é aplicado à produção do texto.

Uma questão que necessitava de uma revisão era a contextualização para a produção do texto. Acostumados ao ambiente da redação, em que o texto é apenas um produto para se verificarem erros de escrita, uma nova atitude precisava ser incorporada à produção do texto: a visão processual. Para tanto, elaboramos uma atividade, com duração semestral, cujo nome passou a ser hemeroteca, nome inspirado no trabalho de coleção de textos que feito por diversas bibliotecas. Passaremos a seguir à compreensão de como concebemos esse trabalho.

\subsection{Hemeroteca como recurso de leitura e produção de textos}

Como uma forma de contextualizar a prática de produção de textos, buscamos na confecção de hemerotecas um trabalho de escrita para, em primeiro lugar, ajudar os alunos a perceberem como a qualidade da leitura interfere na produção textual acadêmica e, em segundo lugar, auxiliá-los na compreensão de conteúdos ministrados pelas diversas disciplinas cursadas durante o semestre letivo. Essa prática visa, sobretudo, habilitar o aluno para retomar seus textos escritos de modo a revisá-lo. A ideia está subsidiada, portanto, na prática da refacção de texto, a qual vem mostrando que é através da releitura que se produzem textos coerentes e coesos.

De forma a atingir tal objetivo, adotamos a prática da hemeroteca, cuja etimologia remete à coleção de textos de jornais e revistas. Geralmente, encontramos hemerotecas em bibliotecas, já que os profissionais que cuidam dela tratam a informação para que os leitores possam buscá-la com maior rapidez. Nesses volumes, os textos publicados nos suportes citados são selecionados e agrupados por assunto. 
A função da hemeroteca neste trabalho é estimular a produção textual. Assim como os bibliotecários, os alunos coletam textos de acordo com um assunto previamente selecionado, relacionado a alguma disciplina cursada no semestre. O tema pode ser indicado ou não pelo professor, dependendo muito mais do interesse do aluno pelo conteúdo tratado nas outras disciplinas.

\subsection{Metodologia de elaboração da hemeroteca}

O primeiro passo para iniciar a montagem da hemeroteca é escolher uma disciplina e, a partir das discussões feitas pelo professor, um assunto que mais tenha atraído o aluno. As fontes para buscar os textos não precisam ficar restritas aos jornais e às revistas. Podem ser coletados textos de internet, desde que seja citada a fonte (o site) e a data de acesso. É importante orientar os alunos para consultarem manuais de normalização, no intuito de que aprendam, por exemplo, a fazer referências bibliográficas de textos que circulam nessa mídia, pois tais textos fazem parte do domínio discursivo acadêmico.

Dessa forma, a cada mês, os alunos devem:

1. escolher um assunto relacionado a uma disciplina: essa deve ser baseada nos critérios do discente e não do professor. Escolher o tema a ser pesquisado motiva os alunos a se interessarem mais pelo seu próprio texto;

2. buscar fontes de leitura: essa atividade deve ser orientada pelos professores, pois nem sempre as fontes de pesquisa utilizadas pelos alunos são confiáveis. É preciso demonstrar para eles a importância desse aspecto na construção do discurso acadêmico;

3. ler estrategicamente os textos, utilizando os princípios das oficinas de leitura: identificação da tese do autor, localização das partes centrais, leitura gradativa, percepção da relação entre os textos, dentre outras;

4. planejar o esquema do texto a ser redigido, sobretudo, respeitando as condições de produção. Esse planejamento consiste em elaborar os subtópicos em que o texto se desdobrará, criar uma linha de raciocínio para esses subtópicos, de forma a garantir a unidade temática, escolher 
os objetivos de cada parágrafo, ${ }^{5}$ elaborar as conclusões e redigir uma introdução;

5. selecionar as citações que farão parte do texto a ser produzido. Essa atividade reforça o uso do argumento da autoridade, prática comum nos textos do meio acadêmico;

6. reescrever o texto quantas vezes forem necessárias antes da entrega definitiva. Essa atividade reforça a ideia de que o aluno deve ser responsável pela revisão do seu texto.

Depois da leitura dos textos selecionados, com ideias novas na mente, é a vez de o aluno produzir o texto dele sobre o mesmo assunto. O formato escolhido é de texto argumentativo, como encontramos em editorias de revistas ou jornais diversos. O professor deve orientar quanto ao número de parágrafos, quais ideias serão selecionadas, qual a ordem delas dentro do texto, dentre outros aspectos de língua padrão e organização textual.

Outra orientação importante é quanto ao processo de produção. O acompanhamento dos progressos do aluno deve ser feito constantemente. O aluno deve perceber que o texto é fruto de um trabalho constante e que deve ser produto de uma reflexão sobre o que se vai escrever e como as informações serão distribuídas no texto de forma a facilitar o processo de leitura pelos futuros interlocutores de seu texto.

Para habilitar o aluno a acompanhar seu progresso, sugerimos criar uma ficha de autoavaliação. Acreditamos ser necessário criar uma lista de procedimentos para que o próprio discente se sinta seguro de que está seguindo na direção mais adequada. Essa lista deve constar tanto aspectos discursivos, quanto gramaticais.

As noções básicas sobre as condições de produção (quem produz, para quem produz, em que gênero, com que objetivo, qual o lugar social de quem fala) são fundamentais para a condução da hemeroteca. Ao ingressarem no ensino superior, grande parte dos alunos ignora essas condições na produção de textos.

\footnotetext{
${ }^{5}$ Emediato (2004) faz um estudo interessante sobre os objetivos do parágrafo e sugere uma série de atividades para serem desenvolvidas com os alunos, sobretudo com os discentes do curso de Administração.
} 
A orientação de como produzir parágrafos também é um aspecto relevante. Os alunos tendem a redigir parágrafos com apenas uma frase, sem fundamentá-los com argumentos, exemplos ou explicações. Notamos que é necessário orientá-los sobre a importância de se delimitarem objetivos para cada parágrafo.

Por outro lado, o trabalho do professor, a cada mês, deve observar os seguintes objetivos:

1 orientar a produção do texto dentro das normas acadêmicas, ajudando os alunos a adequarem o nível de linguagem mais formal;

2 relacionar o conteúdo das aulas à produção da hemeroteca, de acordo com as dificuldades apresentadas pelos alunos;

3 graduar as dificuldades da produção, inserindo citações diretas e indiretas, comentários, análises e sínteses;

4 avaliar o processo de aquisição das habilidades/competências dos alunos.

A avaliação da hemeroteca é feita no final de cada semestre. Como esse trabalho mostra a produção de textos como um processo, o empenho do aluno durante esse período (ao refazer os textos observando as normas para escrita) é o fator de maior peso. A apresentação dentro dos prazos, além da aplicação dos conhecimentos adquiridos durante o semestre, também fazem parte do processo avaliativo.

Do nosso ponto de vista, o trabalho com as hemerotecas possui as seguintes vantagens: proporciona contato com textos de diversos assuntos de interesse do aluno; reforça a refacção contínua do texto; privilegia um tema escolhido pelo aluno; proporciona maior contato com textos argumentativos; aponta a leitura como o princípio do processo de produção de textos; introduz uma nova percepção do processo; aumenta a percepção da evolução da leitura e da escrita pelo próprio aluno; valoriza o processo e o produto; permite tanto um acompanhamento sistemático dos progressos dos alunos, quanto uma visão sistêmica dos conteúdos. 


\section{Considerações finais}

No atual contexto do ensino de Língua Portuguesa, a educação superior ainda não conta com um volume grande de trabalhos que possam orientar o docente, sobretudo no âmbito do tratamento da Língua Portuguesa. No que se refere ao curso de Administração, a prática demonstra que a seleção de conteúdos ainda se baseia nos pressupostos tradicionais, valorizando-se os conhecimentos gramaticais. Isso nos leva a deduzir que a discussão promovida no nível das diretrizes curriculares está aquém do proposto para os níveis fundamental e médio.

Diante disso, percebemos que as questões enunciativas não são alvo do programa dos professores de Português Instrumental. Vemos, assim, a necessidade de uma reformulação dos objetivos da disciplina, haja vista que os alunos ingressantes no ensino superior não possuem habilidades/competências desenvolvidas de forma desejável para discentes de nível superior.

Desse modo, sugerimos que as aulas da disciplina em questão tenham como objetivo o desenvolvimento de estratégias de leitura e de produção de textos, em função dos gêneros que circulam nesse curso. Como proposta, apresentamos que sejam ministradas oficinas de leitura, maximizando o fazer ler, com o propósito do fazer escrever, que também deve ser uma das metas na formação dos acadêmicos.

No tocante à produção de textos, a nossa experiência com a hemeroteca tem se revelado uma boa estratégia, uma vez que, nesse trabalho, as atividades de leitura são utilizadas com objetivo de se criarem novos textos. Além disso, por causa da refacção contínua, as hemerotecas propiciam aos alunos uma constante reflexão sobre o ato de escrita, já que os discentes podem constatar tanto os erros de língua padrão, quanto as questões relativas à adequação do tratamento dado ao assunto, dentre outros, como coerência, coesão e progressão textual.

Esse trabalho apresenta resultados positivos, pois é possível aos próprios alunos verificarem, com o passar do semestre, a evolução de seus textos. O contato constante com leituras e a tentativa de se escrever sobre o que se lê são, do nosso ponto de vista, fatores relevantes para 
a manutenção desse tipo de atividade na disciplina Língua Portuguesa. Numa perspectiva de avaliação multidisciplinar, é possível aos demais docentes que acompanham o grupo de alunos verificar um avanço também no que diz respeito ao aproveitamento dos discentes em suas respectivas disciplinas.

Diante das questões apresentadas aqui, esperamos contribuir efetivamente para a discussão sobre o ensino de Língua Portuguesa no nível superior. É necessário, ao nosso ver, que tal reflexão se estenda a um maior número de cursos, que sejam feitas análises de como vem sendo ministrada tal disciplina no interior desses cursos, para que seja possível aos alunos ingressantes desenvolverem de fato habilidades/ competências no tocante à leitura e à escrita. 


\section{Anexo}

\begin{tabular}{|c|c|c|c|}
\hline & ÇÃO & TEMATIZAÇÃO & ENUNCIAÇÃO \\
\hline $\begin{array}{l}\mathrm{H} \\
\mathrm{A} \\
\mathrm{B} \\
\mathrm{I} \\
\mathrm{L} \\
\mathrm{I} \\
\mathrm{D} \\
\mathrm{A} \\
\mathrm{D} \\
\mathrm{E} \\
\mathrm{S} \\
/ \\
\mathrm{C} \\
\mathrm{O} \\
\mathrm{M} \\
\mathrm{P} \\
\mathrm{E} \\
\mathrm{T} \\
\hat{\mathrm{E}} \\
\mathrm{N} \\
\mathrm{C}\end{array}$ & $\begin{array}{l}\text { produzir textos, } \\
\text { considerando o contexto de } \\
\text { produção, circulação e } \\
\text { recepção; } \\
\text { identificar a finalidade de } \\
\text { gêneros diferentes; } \\
\text { identificar, em textos lidos, } \\
\text { o contexto de produção e } \\
\text { circulação; } \\
\text { inferir a intenção explícita } \\
\text { ou implícita em um dado } \\
\text { texto; estabelecer relação } \\
\text { entre gênero, suporte e } \\
\text { função; } \\
\text { categorizar gêneros de } \\
\text { texto; } \\
\text { interpretar referências } \\
\text { bibliográficas em textos } \\
\text { lidos; } \\
\text { referenciar textos e } \\
\text { suportes, segundo normas } \\
\text { da ABNT }\end{array}$ & $\begin{array}{l}\text { reconhecer a organização } \\
\text { temática de textos de diferentes } \\
\text { gêneros; } \\
\text { identificar e corrigir problemas } \\
\text { de organização temática em } \\
\text { textos apresentados; } \\
\text { produzir textos com organização } \\
\text { temática adequada ao contexto } \\
\text { de produção, aos objetivos do } \\
\text { produtor e ao tema; } \\
\text { relacionar títulos a textos, a partir } \\
\text { de pistas semânticas, gráficas e } \\
\text { estruturais; } \\
\text { usar, produtiva e } \\
\text { autonomamente, a seleção lexical } \\
\text { como estratégia de produção de } \\
\text { sentido e de focalização temática; } \\
\text { identificar efeitos de ironia ou } \\
\text { humor em textos variados; } \\
\text { reconhecer o efeito de sentido } \\
\text { decorrente do uso da pontuação } \\
\text { e de outras notações; } \\
\text { reconhecer o efeito de sentido } \\
\text { decorrente da escolha de uma } \\
\text { determinada palavra ou } \\
\text { expressão; } \\
\text { reconhecer o efeito de sentido } \\
\text { decorrente da exploração de } \\
\text { recursos ortográficos e/ou } \\
\text { morfossintáticos) }\end{array}$ & $\begin{array}{l}\text { reconhecer e usar, } \\
\text { produtiva e } \\
\text { autonomamente, } \\
\text { mecanismos de } \\
\text { representação das vozes em } \\
\text { textos de diferentes } \\
\text { gêneros; } \\
\text { usar, produtiva e } \\
\text { autonomamente, } \\
\text { mecanismos de } \\
\text { modalização e } \\
\text { argumentatividade em } \\
\text { textos de diferentes } \\
\text { gêneros; } \\
\text { identificar a relação lógico- } \\
\text { discursiva produzida pelos } \\
\text { mecanismos de } \\
\text { modalização e } \\
\text { argumentatividade; } \\
\text { produzir textos, } \\
\text { considerando os efeitos de } \\
\text { sentido de relações } \\
\text { intertextuais com outros } \\
\text { textos, discursos, produtos } \\
\text { culturais e linguagens; } \\
\text { reconhecer tipos de } \\
\text { intertextualidade }\end{array}$ \\
\hline
\end{tabular}




\section{Referências}

BONINI, Adair. Veículo de comunicação e gênero textual: noções conflitantes. In: D.E.L.T.A. 19: 1, 2003. p.65-89.

BAKHTIN, M. 1981. Marxismo e filosofia da linguagem. São Paulo: Hucitec, 1981.

CNE Resolução CNE/CP 4, de 13/07/2005, Diretrizes Curriculares Nacionais do Curso de Graduação em Administração. Diário Oficial da União, Brasília, 19 de julho de 2005, Seção 1, p. 26. Disponível em: <http:/ / portal.mec.gov.br/cne/arquivos/pdf/rces004_05.pdf > . Acesso em: 30/01/2009.

DIONÍSIO, Ângela Paiva, BEZERRA, Maria Auxiliadora, MACHADO, Anna Rachel (org). Gêneros textuais e ensino. Rio de Janeiro: Lucerna, 2002.

EMEDIATO, Wander. A fórmula do texto: redação, argumentação e leitura. São Paulo: Geração Editorial, 2004.

HONSBERGER, Janet; GEORGE, Linda. Facilitando oficinas: da teoria à prática. São Paulo: GETS/UWC-CC, 2002. Disponível em: <www.pronaf.gov.br/dater/arquivos/0730612391.pdf> Acesso em 14 de maio de 2008.

MINAS GERAIS. Secretaria Estadual de Educação. Currículo Básico Comum de Lingua Portuguesa. Disponível em <http:// crv.educacao.mg.gov.br>. Acesso em 20 de março de 2008.

OLIVEIRA, Leni Nobre de. Leitura e produção de textos na graduação: um espaço inter e transdisciplinar. Disponível em http:/ / www.alb.com.br/anais16/sem12pdf/sm12ss07_05.pdf. Acesso em 10 de março de 2009.

PERRENOUD, Philippe. A arte de construir competências. In: Nova Escola, Set., 2000. Disponível em <http://www.novaescola.com.br>. Acesso em 20 de dezembro de 2010. 